See Article page 169.

\section{Commentary: It's not the first mistake, it's the second}

\section{Christopher W. Seder, MD}

I firmly believe that in thoracic surgery, it's rarely the first mistake that hurts the patient, it's the second mistake. You are doing a lobectomy and find yourself inside of the pulmonary artery. Quick, put a sponge stick on it, breathe, get a partner and blood in the room, breathe, plan your attack. The next move may be the difference between life and death. If you start blindly and furiously throwing sutures into a stream of dark blood, you've probably made a second mistake. If you put a hole in the back of the artery while trying to get around it, you've made a second mistake. Those are the mistakes that often cost the patient.

In this month's issue of JTCVS, Guenthart and colleagues ${ }^{1}$ report their technique for repair of an atrialesophageal fistula after catheter ablation for atrial fibrillation. The authors provide multiple pearls to navigate the diagnosis and successful repair of this rare, but lethal, complication. Patients who present with atrial-esophageal fistula have already experienced one "mistake" in the cath lab, and this manuscript acts as a guide for cardiothoracic surgeons to avoid a second mistake that could be deadly. The pearls include obtaining a prone computed tomography scan to identify the fistula, foregoing initial esophagoscopy and keeping the patient in Trendelenburg to avoid air embolism, and addressing the atrial defect first. The authors describe a patch repair of the back wall of the left atrium on cardiopulmonary bypass to avoid tearing the friable and inflamed atrial wall. This is followed by thoracotomy and mobilization of the esophagus with ligation of the fistula and intercostal muscle transposition to permanently separate the esophagus and atrium.

\footnotetext{
From the Department of Cardiovascular and Thoracic Surgery, Rush University Medical Center, Chicago, Ill.

Disclosures: The author reported no conflicts of interest.

The Journal policy requires editors and reviewers to disclose conflicts of interest and to decline handling or reviewing manuscripts for which they may have a conflict of interest. The editors and reviewers of this article have no conflicts of interest.

Received for publication July 28, 2020; revisions received July 28, 2020; accepted for publication July 31, 2020; available ahead of print Aug 11, 2020.

Address for reprints: Christopher W. Seder, MD, 1725 W. Harrison St, Suite 774, Chicago, IL 60305 (E-mail: Christopher_W_Seder@rush.edu).

JTCVS Techniques 2020;4:175

2666-2507

Copyright ( $\subset 2020$ The Authors. Published by Elsevier Inc. on behalf of The American Association for Thoracic Surgery. This is an open access article under the CC BY-NCND license (http://creativecommons.org/licenses/by-nc-nd/4.0/).

https://doi.org/10.1016/j.xjtc.2020.07.029
}

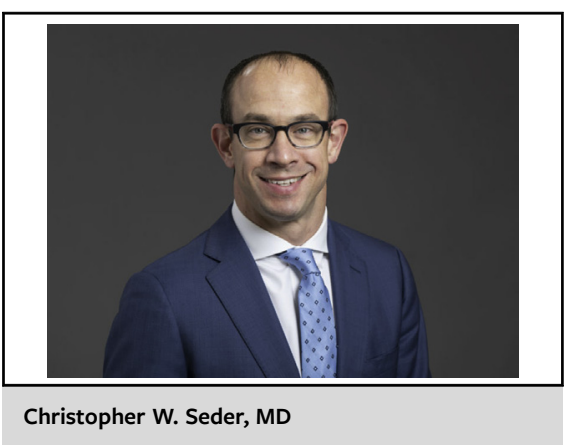

CENTRAL MESSAGE

Early recognition, emergent

management, and cardiac repair

before endoscopy are key when

faced with an atrial-esophageal

fistula.

I congratulate the authors on this interesting and important guide to the diagnosis and management of atrialesophageal fistula. It is an underrecognized complication that is likely to increase in frequency as the rate of catheter-based ablation rises. Although it is not the first time atrial-esophageal fistula or this approach have been described, this manuscript serves to reiterate the principles of early recognition, emergent management, and cardiac repair before endoscopy. When surgeons are faced with this challenging complication, hopefully this article will act as a guide to avoid making a dreaded second mistake!

\section{Reference}

1. Guenthart BA, Sun B, De Biasi A, Fischbein MP, Liou DZ. Surgical technique for atrial-esophageal fistula repair after catheter ablation: an underrecognized complication. J Thorac Cardiovasc Surg Tech. 2020;4:169-72. 